\title{
Chemical and antioxidant parameters of dried forms of ginger rhizomes
}

Aicha Jelled $^{\mathrm{a}}$, Ângela Fernandes ${ }^{\mathrm{b}}$, Lillian Barros ${ }^{\mathrm{b}}$, Hassiba Chahdoura ${ }^{\mathrm{b}, \mathrm{c}}$, Lotfi Achour ${ }^{\mathrm{c}}$, Isabel

C.F.R. Ferreira ${ }^{\text {b, }}{ }^{*}$, Hassen Ben Cheikh $^{\mathrm{a}}$

${ }^{a}$ Laboratoire d'Histologie et de cytogénétique et maladie de l'enfant UR12ES10, Faculté de Médecine, Université de Monastir, Tunisie.

${ }^{c}$ Mountain Research Centre (CIMO) ESA, Polytechnic Institute of Bragança, Campus de Santa Apolónia, 1172, 5301-855 Bragança, Portugal.

${ }^{b}$ Laboratoire de recherche Bioressources: Biologie Intégrative \& Valorisation, Institut supérieur de biotechnologie, Université de Monastir, Tunisie.

*Author to whom correspondence should be adressed (Tel.: +351 273 303219; fax: +351 273 325405. E-mail address: iferreira@ipb.pt (I.C.F.R. Ferreira). 


\begin{abstract}
There are various products that can be obtained from ginger (Zingiber officinale Roscoe) rhizomes, such as dried products, being difficult to choose the best option for antioxidant purposes. In this study, three different dried forms of ginger rhizomes (freshly dried, dried and powder dried) were characterized in terms of chemical composition including individual profiles in sugars, organic acids, fatty acids, tocopherols, and antioxidants (phenolics and flavonoids). The in vitro antioxidant properties (free radicals scavenging activity, reducing power and lipid peroxidation inhibition) of their methanolic extracts were also evaluated. The results of this study indicate that the ginger form has significant influence in chemical and antioxidant parameters of the plant; dried ginger (DG) proved to be the best choice. Overall, this study could help the consumer in the selection of the most suitable option regarding antioxidant purposes.
\end{abstract}

Keywords: Zingiber officinale; Ginger; Dried forms; Chemical composition; Antioxidant 


\section{Introduction}

Phytochemicals are biological active compounds occurred from plants. Recently, there has been growing interest in the useful effects of plant phytochemicals and their impact for the maintenance of health and prevention of disease (Gruenwald et al., 2010; Kim et al., 2012). Spices are also rich sources of phytochemicals (Das et al., 2012) and, particularly, Zingiber officinale Roscoe (Ginger) has been used as a spice and as natural additive for more than 2000 years (Bartley and Jacobs, 2000). Ginger belongs to the family Zingiberaceae and it is cultivated in many countries and commercialized to other parts of the world. Its dried rhizomes are consumed as a spice and flavouring agent and are attributed to have many medicinal properties (Gupta, 2008).

Recently, ginger has received growing interest because of its anti-inflammatory (Minghetti et al., 2007) and antidiabetic (Afshari et al., 2007) properties. Pharmacological research also revealed that ginger has anticancer, chemopreventive and chemotherapeutic effects on a variety of tumor cell lines and on animal models (Shukla and Singh, 2007; Cheng et al., 2011). The majority of the studies highlight ginger antioxidant activity (El Ghorab et al., 2010; Mesomo et al., 2012; Oboh et al., 2012), related to the prevention of a number of diseases (Adel and Prakash, 2010; Gupta et al., 2014; Liu et al., 2014; Przygodzka et al., 2014).

However, the content in bioactive compounds can be influenced by several factors including growing conditions, climate, time of harvesting, and post-harvesting factors (e.g., storage conditions and processing), and varies not only in different parts of the plant but also from country to country (Masullo et al., 2015). An important factor in dry plants is the dehydration process. The most generalized used methods are shade drying (natural drying) and hot air drying, because of their lower cost in comparison with other dehydration processes. Nonetheless, natural drying is not suitable to handle large quantities of material, and might 
compromise the quality standards (Soysal and Oztekin, 2001), namely in what concerns to contamination or adulteration of the herbal products (Pinela et al., 2011).

The reduction of the moisture content inherent to drying processes is normally related with a microbial growth inhibition and prevention of some biochemical modifications, however, it also promotes a loss of aroma and changes in nutritional, physical (Phoungchandang and Saentaweesuk, 2010; Pinela et al., 2011), and antioxidant (Chan et al., 2009) properties.

There is available in the market a huge diversity of plant formulations, being desirable to know the most adequate form for each specific benefit (Pereira et al., 2014). For example, ginger rhizomes are commercially available at the natural stage (fresh vegetables without processing), but also in concentrated ginger powders, and dried products (Phoungchandang and Saentaweesuk, 2011).

Due to the absence of studies comparing ginger forms available for commercialization, it is hard to choose the best option for consumption and for further scientific works. Therefore, the aim of the present study was to characterize chemical and antioxidant parameters of three different forms of ginger rhizomes available in market, and provide consumers with a comparative overview to guide their choice.

\section{Material and methods}

\subsection{Samples and sample's preparation}

Different forms of Zingiber officinalis rhizomes (fresh ginger, dried ginger- DG and powder dried ginger- PDG) were purchased from the local market. Fresh ginger was washed, cleaned, cuted into small pieces and air-dried (FDG) under constant weight. FDG and DG samples (obtained after a natural shade drying process) were further reduced to a fine dried powder for subsequent analyses. 


\subsection{Standards and reagents}

The HPLC-grade solvents ethyl acetate (99.8\%), n-hexane (97\%) and acetonitrile (99.9\%) were purchased from Fisher Scientific (Lisbon, Portugal). The standard 47885-U (fatty acids methyl ester- FAME mixture), L-ascorbic acid, sugar standards (D(-)-fructose, $\mathrm{D}(+)$-glucose, $\mathrm{D}(+)$-melezitose, $\mathrm{D}(+)$-sucrose and $\mathrm{D}(+)$-trehalose) and the standard used in the antioxidant activity assays (6-hydroxy-2,5,7,8-tetramethylchroman-2-carboxylic acid; trolox) were from Sigma (St. Louis, MO, USA). Tocopherol standards ( $\alpha-, \beta-, \gamma$-, and $\delta$-isoforms) and the racemic tocol $(50 \mathrm{mg} / \mathrm{mL})$ used as internal standard in tocopherol's analysis were obtained from Matreya (Pleasant Gap, PA, USA). 2,2-Diphenyl-1-picrylhydrazyl (DPPH), used in antioxidant activity assays (free radicals scavenging activity), was obtained from Alfa Aesar (Ward Hill, MA, USA). Water was treated in a Milli-Q water purification system (TGI Pure Water Systems, Greenville, SC, USA).

\subsection{Chemical parameters}

2.3.1. Sugars. Melezitose was used as the internal standard (IS) being incorporated in the extraction procedure previously described by the authors (Guimarães et al., 2013a). The high performance liquid chromatography (HPLC) equipment (Knauer Smartline, Berlin, Germany) included a pump, a degasser system, and a refraction index (RI) detector. An auto-sampler (AS-2057 Jasco, Easton, MD, USA) and a data analyzer Software (Clarity 2.4 DataApex) were also used. The chromatographic separation conditions were as follows: Eurospher 100-5 $\mathrm{NH}_{2}$ column $\left(4.6 \times 250 \mathrm{~mm}, 5 \mu \mathrm{m}\right.$, Knauer, Berlin, Germany) at $35^{\circ} \mathrm{C}$; acetonitrile/deionized water, $70: 30(\mathrm{v} / \mathrm{v})$, as mobile phase, at $1 \mathrm{~mL} / \mathrm{min}$. The identification was performed by comparison with standards, and the quantification was carried out by using the internal standard method. The results were expressed in $\mathrm{g}$ per $100 \mathrm{~g}$ of dry weight. 
2.3.2. Organic acids. The extraction procedure was previously described by the authors (Pereira et al., 2013). The equipment was a Shimadzu 20A series UFLC (Shimadzu Corporation, Kyoto, Japan). The chromatographic separation conditions were as follows: Sphere Clone (Phenomenex, Torrance, CA, USA) reverse phase $\mathrm{C}_{18}$ column (5 $\mu \mathrm{m}, 250 \mathrm{~mm} \times$ $4.6 \mathrm{~mm}$ i.d.), at $35^{\circ} \mathrm{C}$; sulphuric acid $(3.6 \mathrm{mM})$ as mobile phase at $0.8 \mathrm{~mL} / \mathrm{min}$. It was used a photodiode array detector (PDA) at 215 and $245 \mathrm{~nm}$ (for ascorbic acid) as preferred wavelengths. The quantification was performed by comparison of the area of the peaks recorded at $215 \mathrm{~nm}$ with calibration curves of commercial standards. The results were expressed in g per $100 \mathrm{~g}$ of dry weight.

2.3.3. Fatty acids. The extraction procedure was previously described by the authors (Guimarães et al., 2013a). The gas-chromatography equipment (DANI GC 1000, Contone, Switzerland) included a split/splitless injector, a flame ionization detector (FID) at $260^{\circ} \mathrm{C}$, and a CSW 1.7 Software (DataApex 1.7). The chromatographic separation conditions were as follows: Macherey-Nagel (Düren, Germany) column (50\% cyanopropyl-methyl-50\% phenylmethylpolysiloxane, $30 \mathrm{~m} \times 0.32 \mathrm{~mm}$ i.d. $\times 0.25 \mu \mathrm{m} \mathrm{d}_{\mathrm{f}}$ ); the initial temperature of the column was $50^{\circ} \mathrm{C}$, held for $2 \mathrm{~min}$, then a $30^{\circ} \mathrm{C} / \mathrm{min}$ ramp to $125^{\circ} \mathrm{C}, 5^{\circ} \mathrm{C} / \mathrm{min}$ ramp to $160^{\circ} \mathrm{C}$, $20^{\circ} \mathrm{C} / \mathrm{min}$ ramp to $180^{\circ} \mathrm{C}, 3^{\circ} \mathrm{C} / \mathrm{min}$ ramp to $200^{\circ} \mathrm{C}, 20^{\circ} \mathrm{C} / \mathrm{min}$ ramp to $220^{\circ} \mathrm{C}$ and held for 15 min; carrier gas (hydrogen) at $4.0 \mathrm{~mL} / \min (0.61$ bar $)$, measured at $50^{\circ} \mathrm{C}$; split injection $(1: 40)$ at $250^{\circ} \mathrm{C}$. The identification was performed by comparison of the relative retention times of samples FAME peaks with standards. The results were expressed in $\mathrm{g} / 100 \mathrm{~g}$ fat.

2.3.4. Tocopherols. Racemic tocol was used as IS, being incorporated in the extraction procedure previously described by the authors (Guimarães et al., 2013a). The HPLC 
equipment was described in section 2.3.1., but with a fluorescence detector (FP-2020; Jasco, Easton, MD, USA) programmed for excitation at $290 \mathrm{~nm}$ and emission at $330 \mathrm{~nm}$. The chromatographic separation conditions were as follows: a Polyamide II $(5 \mu \mathrm{m}, 250 \mathrm{~mm} \times 4.6$ $\mathrm{mm}$ i.d.) normal- phase column (YMC Waters, Dinslaken, Germany) at $35^{\circ} \mathrm{C}$; a mixture of nhexane and ethyl acetate $(70: 30, \mathrm{v} / \mathrm{v})$ as mobile phase, at $1 \mathrm{~mL} / \mathrm{min}$. The identification was performed by comparison with standards, and the quantification was based on calibration curves obtained from commercial standards using the IS method. The results were expressed in $\mathrm{mg}$ per $100 \mathrm{~g}$ of dry weight.

\subsection{Antioxidant parameters}

2.4.1. Extraction procedure. Each sample of Zingiber officinalis rhizomes (1 g) was extracted submitted to a solid-liquid extraction with $25 \mathrm{~mL}$ of methanol $\left(25^{\circ} \mathrm{C}\right.$ at $\left.150 \mathrm{rpm}\right)$ during $1 \mathrm{~h}$. After filtration with Whatman $\mathrm{N}^{\mathrm{o}} 4$ paper, the obtained residue was re-extracted in the same conditions of the ones previously used. The methanol was removed at $40^{\circ} \mathrm{C}$ (rotary evaporator Büchi R-210) and the remaining extracts were re-dissolved in methanol (final concentration, $5 \mathrm{mg} / \mathrm{mL}$ ). These final solutions were further diluted to different concentrations to be used in the subsequent assays.

2.4.2. Phenolics and flavonoids. Total phenolics were estimated according with Wolfe et al. (2003). Briefly, Folin Ciocalteu reagent (5 mL, diluted with water 1:10 v/v) and sodium carbonate $(75 \mathrm{~g} / \mathrm{L}, 4 \mathrm{~mL})$ were added to the extract solutions $(1 \mathrm{~mL})$, vortexed for $15 \mathrm{~s}$ and allowed to stand for $30 \mathrm{~min}$ at $40^{\circ} \mathrm{C}$. The absorbance was measured at $765 \mathrm{~nm}$ and gallic acid was used to obtain the standard curve $\left(0.05-0.8 \mathrm{mM} ; y=1.9799 x+0.0299 ; R^{2}=0.9997\right)$. The results were expressed as mg of gallic acid equivalents (GAEs) per g of extract. 
Total flavonoids were estimated according with Jia et al. (1999). Briefly, the extract solutions $(0.5 \mathrm{~mL})$ were mixed with distilled water $(2 \mathrm{~mL})$ and $\mathrm{NaNO}_{2}$ solution $(5 \%, 0.15 \mathrm{~mL})$, for 6 min. $\mathrm{AlCl}_{3}$ solution $(10 \%, 0.15 \mathrm{~mL})$ was added for $6 \mathrm{~min}$ and, then, $\mathrm{NaOH}$ solution $(4 \%, 2 \mathrm{~mL})$ was added. Immediately, distilled water was also added up to the final volume of $5 \mathrm{~mL}$ and the mixture was allowed to stand for $15 \mathrm{~min}$. The absorbance was measured at $510 \mathrm{~nm}$ and (+)-catechin was used to obtaine the standard curve $(0.0156-$ $\left.1.0 \mathrm{mM} ; y=0.9186 x-0.0003 ; R^{2}=0.9999\right)$. The results were expressed as $\mathrm{mg}$ of $(+)-$ catechin equivalents (CEs) per g of extract.

2.4.3. Antioxidant activity assays. The following assays were carried out to evaluate the antioxidant activity of the sample: DPPH radical-scavenging activity and reducing power, both performed with a microplate reader (ELX800 Bio-Tek Instruments, Inc; Winooski, VT, USA) at 515 and $690 \mathrm{~nm}$, respectively, and $\beta$-carotene bleaching inhibition and thiobarbituric acid reactive substances (TBARS) assay, both performed in a spectrophotometer (AnalytikJena, Jena, Germany) at 470 and $532 \mathrm{~nm}$, respectively. All the details were previously described by the authors (Pinela et al., 2011; Guimarães et al., 2013b) and the results were expressed in $\mathrm{EC}_{50}$ values (sample concentration providing $50 \%$ of antioxidant activity or 0.5 of absorbance in the reducing power assay).

\subsection{Statistical analysis}

Three samples of each form of Zingiber officinalis rhizomes were used in the analyses, being the assays performed in triplicate. Mean values and standard deviation (SD) were used to express the results, which were also submitted to an one-way analysis of variance (ANOVA) followed by Tukey's HSD Test with a = 0.05, by using the SPSS v. 20.0 program. 


\section{Results and discussion}

\subsection{Effects on chemical parameters}

Fructose, glucose and sucrose were found in higher amounts in DG (Table 1); sucrose was found only in this sample. Curiously, it was not possible to quantify any sugar in FDG sample, the amount may be very low to be detected (Figure 1A). Four organic acids were identified: oxalic, malic, citric and fumaric acids (Table 1), with oxalic acid as the most abundant one. Malic and citric acids were not detected in both FDG and PDG, only existing in DG in small amounts (Figure 1B). This sample revealed the highest organic acids content. Yeh et al. (2014) recently reported the presence of tartaric and succinic acids in two ginger varieties, but not fumaric acid. Tartaric, malic, citric or succinic acids are examples of organic acids that might play a protective role against different diseases due to their antioxidant activity, related with the capacity to chelate metals or to delocalize the electronic charge coming from free radicals (Seabra et al., 2006). The presence of citric and malic acids only in DG might be related with its higher antioxidant properties (discussed later).

The main fatty acids found in the studied ginger samples, as also the relative percentages of total saturated fatty acids (SFA), monounsaturated fatty acids (MUFA) and polyunsaturated fatty acids (PUFA) are given in Table 2. Up to 25 fatty acids were detected in almost all the samples. The comparison between the three fatty acid profiles showed a high variability of PUFA (ranging from $9.58 \%$ in FDG to $42.42 \%$ in PDG). SFA was the main group for FDG and DG (58.34 and 56.85\%, respectively), with the main contribution of palmitic acid (C16:0) (Figure 2). MUFA represented $17.88 \%$ and $32.08 \%$ in DG and FDG, respectively, with the main constituent being linoleic acid (C18:2n6), followed by oleic acid (C18:1n9). In the present study, PUFA/SFA ratios were $0.16 ; 0.44$ and 1.14 for FDG, DG and PDG, respectively. In comparison with the other two samples, the PDG seems to be the most adequate for consumption, containing the highest level of unsaturated fatty acids, as also the 
highest PUFA/SFA ratio (Guil et al., 1996). A completely different fatty acids profile was described by Adeyeye et al. (2014): $7.14 \mathrm{~g} / 100 \mathrm{~g}$ of total fatty acids, with $65.4 \%$ of PUFA and $17.5 \%$ of SFA; the most abundant fatty acid was linoleic acid representing $52.7 \%$ of the total fatty acids content, followed by linolenic acid, representing $18.1 \%$ and oleic acid with $13 \%$. Tocopherols content was higher in DG and PDG, which showed similar results (Table 2); $\beta$ tocopherol was the most abundant form in all samples, while $\delta$-tocopherol was not detected in DG nor in FDG. Otherwise, FDG sample did not show the presence of $\alpha$-tocopherol and $\delta$ tocopherol. Tocopherols are important natural antioxidants in plant foods, especially those rich in PUFA, being able to scavenge lipid peroxyl radicals derived from unsaturated lipid molecules, and therefore, preventing the propagation of lipid peroxidation (Traber, 2007). Due to this free radical scavenging activity, tocopherols could also protect against degenerative processes, such as cancer and cardiovascular diseases (Burton and Traber, 1990; Kagan et al, 2003). To the author's knowledge, this is the first report on ginger tocopherols.

\subsection{Effects on antioxidant parameters}

Table 3 shows the results of total phenolic contents of the three ginger methanolic extracts. DG had the highest content, while PDG gave the lowest level, which can be attributed to polyphenols auto-oxidation or degradation during drying, powdering and storage of this latter sample. The total phenolic content obtained in the present study was higher than the values described by Sattar et al. (2013) for ginger extracts obtained with methanol $(10 \pm 0.12$ to $14 \pm 0.03 \mathrm{mg} \mathrm{GAE} / \mathrm{g}$ dry material). Furthermore, total phenolics in sun, oven, vacuum oven and freeze dried gingers were described as $319.60 \pm 33.45,354.05 \pm 40.60,284.10 \pm 18.10$ and

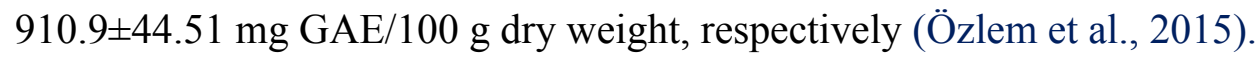

Among phenolics, flavonoids function as metal chelators, reducing agents, chain-breaking antioxidants and quenchers of the formation of singlet oxygen (Ghimeray et. al., 2009). DG 
extract showed the highest amounts of flavonoids. Sattar et al. (2013) described total flavonoids ranging from $5.33 \pm 0.75$ to $8.34 \pm 2.1 \mathrm{mg} \mathrm{CE} / \mathrm{g}$ of dry material in ethanol, acetone, methanol and n-hexane extracts.

The DG methanolic extract was the most able to reduce the stable free radical 2,2-diphenyl-1picrylhydrazyl (DPPH) to the yellow-colored DPPH (Table 4). DG also showed the highest ferric reducing capacity, while PDG revealed the lowest capacity. This can be explained by higher alterations in the antioxidants composition due to storage in powder form.

The capacity to inhibit the $\beta$-carotene bleaching evaluates the antioxidant activity of the samples in emulsions where the coupled oxidation of $\beta$-carotene and linoleic acid occur. Once more, DG methanolic extract showed the highest antioxidant activity in this assay.

All the samples proved to have high TBARS inhibition capacity being more significant in DG. PDG presented the lowest antioxidant properties, which is compatible to its lower phenolics and flavonoids content. Shan et al. (2005) previously confirmed that phenolic compounds significantly contribute to spices antioxidant properties.

Overall, the present study has provided some comparative information on the chemical composition and antioxidant activity of three forms of ginger roots. DG was the sample with the highest antioxidant activity in agreement with its higher bioactive compounds content. It seems that drying the whole rhizomes without cutting it prevent adulteration and conserve the composition inside.

\section{Acknowledgements}

The authors are grateful to Fundação para a Ciência e a Tecnologia (FCT, Portugal) for financial support to CIMO (strategic project PEst-OE/AGR/UI0690/2014), A. Fernandes grant (SFRH/BD/76019/2011) and L. Barros researcher contract under "Programa 
Compromisso com Ciência-2008”. A. Jelled thanks M. Khaled Ben Abdessalem for his uncountable support.

\section{References}

Adel, S. P. R., Prakash, J. 2010. Chemical composition and antioxidant properties of ginger root (Zingiber officinale). J. Med. Plant. Res. 4, 2674-2679.

Adeyeye, E. I., Adeolu, J. A, Fagbohun, E. D. 2014. Lipid Composition of Afromomum melegueta, Zingiber officinale, Afromomum melegueta \& Xylopic aethiopica. BMR Food Nutri. Res. 1, 1-16

Afshari, A. T., Shirpoor, A., Farshid, A., Saadatian, R., Rasmi, Y., Saboory, E., Ilkhanizadeh, B., Allameh A. 2007. The Effect of Ginger on Diabetic Nephropathy, Plasma Antioxidant Capacity and Lipid Peroxidation in Rats. Food Chem. 101, 148-153.

Bartley, J., Jacobs, A. 2000. Effects of drying on flavour compounds in Australian grown ginger (Zingiber officinale). J. Sci Food Agric. 80, 209-215.

Burton, G. W., Traber, M. G. 1990. Vitamin E: Antioxidant activity, biokinetics, and bioavailability. Ann. Rev.Nutri. 10, 357-382.

Chan, E., Lim, Y. Y., Wong, S. K., Lim, K. K., Tan, S. P., Lianto, F. S., Yong, M. Y. 2009. Effects of different drying methods on the antioxidant properties of leaves and tea of ginger species. Food Chem. 113, 166-172.

Cheng, X. L., Liu, Q., Peng, Y. B., Qi, L. W., Li, P. 2011. Steamed Ginger (Zingiber officinale): Changed Chemical Profile and Increased Anticancer Potential. Food Chem. $129,1785-1792$. 
Das, L., Bhaumik, E., Raychaudhuri, U., Chakraborty, R. 2012. Role of nutraceuticals in human health. J. Food Sci. Technol. 49, 173-183.

El-Ghorab, A. H., Nauman, M., Anjum, F. M., Hussain, S. and Nadeem, M. 2010. A Comparative Study on Chemical Composition and Antioxidant Activity of Ginger (Zingiber officinale) and Cumin (Cuminum cyminum). J. Agric. Food Chem. 58, 82318237.

Ghimeray, A. K, Jin, C., Ghimire, B. K and Cho, D. H. 2009. Antioxidant activity and quantitative estimation of azadirachtin and nimbin in Azadirachta indica A. Juss grown in foothills of Nepal. Afr. J. Biotechnol. 8, 3084-3091.

Gruenwald, J., Freder, J., Armbruester, N. 2010. Cinnamon and health. Crit. Rev. Food Sci. Nutr. 50, 822-834.

Guil, J. L., Torija, M.E., Gimenez, J. J., Rodriguez, I. 1996. Identification of fatty acids in edible wild plants by gas chromatography. J. Chrom. A 719, 229-235.

Guimarães, R., Barros, L., Dueñas, M., Calhelha, R. C., Carvalho, A. M., Santos-Buelga, S., Ferreira, I.C.F.R. 2013a. Nutrients, phytochemicals and bioactivity of wild Roman chamomile: A comparison between the herb and its preparations. Food Chem. 136, 718725.

Guimarães, R., Barros, L., Dueñas, M., Calhelha, R. C., Carvalho, A. M., Santos-Buelga, S., Ferreira, I.C.F.R. 2013b. Infusion and decoction of wild German chamomile: Bioactivity and characterization of organic acids and phenolic compounds. Food Chem. 136, 947954.

Gupta, R. K. 2008. Ginger. A Wonderful Spice: An Overview. Vegetos, 21, 1-10. 
Gupta, S.K., Sharma, A. (2014).Medicinal properties of Zingiber officinale Roscoe - A Review. IOSR J. Pharm. Biol. Sci. 9, 124-129.

Jia, Z., Tang, M., Wu, J. 1999. The determination of flavonoid contents in mulberry and their scavenging effects on superoxide radicals. Food Chem. 64, 555-559.

Kagan, V. E., Kuzmenko, A. I., Shvedova, A. A., Kisin, E. R. Li. R., Martin I., Quinn, P. J., Tyurin, V. A., Tyurina Y. Y., Yalowich, J. C. 2003. Direct evidence for recycling of myeloperoxidase-catalyzed phenoxyl radicals of a vitamin E homologue,2,2,5,7,8pentamethyl-6-hydroxy chromane, by ascorbate/dihydrolipoate in living HL-60 cells. Bioch. Biophys. Acta 1620, 72-84.

Kim, I. L., Yang, M., Goo, T. H., Jo, C., Ahn, D. U., Park, J. H., Lee, O.H., Kang, S. N. 2012. Radical scavenging-linked antioxidant activities of commonly used herbs and spices in Korea. Int. J. Food Sci. Nutr. 63, 603-609.

Liu, W., Zhou, C. L, Zhao, Chen, D., Li, Q. H. (2014). Optimized microwave-assisted extraction of 6-gingerol from Zingiber officinale roscoe and evaluation of antioxidant activity in vitro. Acta Sci. Pol., Technol. Aliment. 13, 155-168.

Masullo, M. Montoro, P. Mari, A. Pizza C., Piacente, S. 2015. Medicinal plants in the treatment of women's disorders: analytical strategies to assure quality, safety and efficacy. J Pharm. Biomed. Anal. Doi: 10.1016/j.jpba.2015.03.020

Mesomo, M. C., Scheer, A. P., Perez, E., Ndiaye, P. M. and Corazza, M. L. 2012. Ginger (Zingiber officinale R.) Extracts Obtained Using Supercritical CO2 and Compressed Propane: Kinetics and Antioxidant Activity Evaluation. J. Supercrit. Fluids 71, 102-109. 
Minghetti, P., Sosa, S., Cilurzo, F., Casiraghi, A., Alberti, E., Tubaro, A., Loggia, R. D. and Montanari, L. 2007. Evaluation of the Topical Anti-inflammatory Activity of Ginger Dry Extracts from Solutions and Plasters. Planta Med. 73, 1525-1530.

Oboh, G., Akinyemi, A. J. and Ademiluyi, A. O. 2012. Antioxidant and Inhibitory Effect of Red Ginger (Zingiber officinale var. Rubra) and White Ginger (Zingiber officinale Roscoe) on Fe2+ Induced Lipid Peroxidation in Rat Brain. In vitro. Exp. Toxicol. Pathol. $64,31-36$.

Özlem, A. G., Alev, A. B, Nuran, E., Omca, D. 2015. Drying effects on the antioxidant properties of tomatoes and ginger. Food Chem. 173, 156-162.

Pereira, C., Barros, L., Carvalho, A. M., Ferreira, I. C. F. R. 2013. Use of UFLC-PDA for the analysis of organic acids in thirty-five species of food and medicinal plants. Food Anal Method. 6, 1337-1344.

Pereira, C., Barreira, J. C. M,. Calhelha, R. C., Queiroz, M. J. R. P. Barros, L., Ferreira I. C. F. R. 2014. New insights on the effects of formulation type and compositional mixtures over the antioxidant and cytotoxic activities of dietary supplements based-on hepatoprotective plants. Food Funct. 5, 2052-2060.

Phoungchandang, S., Saentaweesuk, S. 2011. Effect of two stage, tray and heat pump assisted-dehumidified drying on drying characteristics and qualities of dried ginger. Food Bioprod. Process. 89, 4, 429-437.

Pinela, J., Barros, L, Carvalho, A. M., Ferreira I. C. F. R. 2011. Influence of the drying method in the antioxidant potential and chemical composition of four shrubby flowering plants from the tribe Genisteae (Fabaceae). Food Chem Toxicol. 49, 2983-2989. 
Przygodzka,M., Zielinska, D., Ciesarová, Z., Kukurová, K., Zielinski, H. 2014. Comparison of methods for evaluation of the antioxidant capacity and phenolic compounds in common spices. LWT - Food Sci. Technol. 58, 321-326.

Sattar, N. A., Hussain, F., Iqbal, T. 2013. Antioxidant activities of Z. officinale Roscoe and $A$. allughas Roscoe (Zingiberaceae) Rhizomes. Bangladesh J. Sci. Ind. Res. 48, 115-118.

Seabra, R. M., Andrade, P. B., Valentão, P., Fernandes, E., Carvalho, F., Bastos, M. L. 2006. Anti-oxidant compounds extracted from several plant materials. Biomaterials from aquatic and terrestrial organisms. New Hampshire: Science Publishers, Enfield (NH) Jersey Plymouth.

Shan, B., Cai, Y. Z., Sun, M., Corke, H. 2005. Antioxidant capacity of 26 spice extracts and characterization of their phenolic constituents. J Agric Food Chem. 53, 7749-7759.

Shukla, Y., Singh, M. 2007. Cancer Preventive Properties of Ginger: A Brief Review. Food Chem. Toxicol. 45, 683-690.

Soysal, Y., Öztekin, S. 2001. Technical and economic performance of a tray dryer for medicinal and aromatic plants. J. Agric. Eng. Res. 79, 73-79.

Traber, M. G. 2007. Vitamin E regulatory mechanisms. Ann. Rev. Nutri. 27, 347-362.

Wolfe, K. Wu, X. Liu, R. H. 2003. Antioxidant activity of apple peels. J Agric. Food Chem. $51,609-614$.

Yeh, H. Y., Chuang, C. H., Chen, H. C., Wan, C. J, Chen, T., Lin L. Y. 2014. Bioactive components analysis of two various gingers (Zingiber officinale Roscoe) and antioxidant effect of ginger extracts. LWT - Food Sci Technol. 55, 329-334. 
Table 1. Composition in individual sugars and organic acids of the studied ginger dried forms.

\begin{tabular}{llll}
\hline & FDG & DG & PDG \\
\hline Fructose & nd & $2.45 \pm 0.05^{\mathrm{b}}$ & $4.06 \pm 0.16^{\mathrm{a}}$ \\
Glucose & nd & $2.18 \pm 0.07^{\mathrm{a}}$ & $2.11 \pm 0.17^{\mathrm{a}}$ \\
Sucrose & nd & $4.67 \pm 0.09$ & nd \\
Sum $(\mathrm{g} / 100 \mathrm{~g})$ & nd & $9.30 \pm 0.21^{\mathrm{a}}$ & $6.17 \pm 0.33^{\mathrm{b}}$ \\
& & & \\
Oxalic acid & $1.89 \pm 0.01^{\mathrm{b}}$ & $1.63 \pm 0.01^{\mathrm{c}}$ & $2.16 \pm 0.01^{\mathrm{a}}$ \\
Malic acid & nd & $0.70 \pm 0.01$ & nd \\
Citric acid & nd & $0.61 \pm 0.02$ & nd \\
Fumaric Acid & tr & $0.09 \pm 0.01$ & tr \\
Sum $(\mathrm{g} / 100 \mathrm{~g})$ & $1.89 \pm 0.01^{\mathrm{c}}$ & $3.03 \pm 0.01^{\mathrm{a}}$ & $2.16 \pm 0.01^{\mathrm{b}}$ \\
\hline
\end{tabular}

FDG: freshly dried ginger; DG: dried ginger; PDG: powder dried ginger; nd (not detected). In each line different letters mean significant differences $(p<0.05)$. 
Table 2. Composition in fatty acids and tocopherols of the studied ginger dried forms.

\begin{tabular}{|c|c|c|c|}
\hline & FDG & DG & PDG \\
\hline C6:0 & $2.25 \pm 0.14$ & $3.97 \pm 0.13$ & $3.33 \pm 0.09$ \\
\hline $\mathrm{C} 8: 0$ & $1.82 \pm 0.08$ & $2.45 \pm 0.01$ & $1.60 \pm 0.01$ \\
\hline C10:0 & $4.85 \pm 0.16$ & $6.25 \pm 0.24$ & $4.83 \pm 0.01$ \\
\hline C11:0 & nd & $0.08 \pm 0.01$ & nd \\
\hline C12:0 & $3.34 \pm 0.06$ & $4.65 \pm 0.08$ & $2.69 \pm 0.01$ \\
\hline C13:0 & $0.36 \pm 0.03$ & $0.08 \pm 0.01$ & $0.05 \pm 0.01$ \\
\hline C14:0 & $4.17 \pm 0.08$ & $4.59 \pm 0.06$ & $1.35 \pm 0.03$ \\
\hline $\mathrm{C} 14: 1$ & $0.33 \pm 0.03$ & $0.22 \pm 0.01$ & $0.06 \pm 0.01$ \\
\hline C15:0 & $0.70 \pm 0.09$ & $0.70 \pm 0.06$ & $0.21 \pm 0.01$ \\
\hline C15:1 & $0.99 \pm 0.01$ & $0.76 \pm 0.02$ & $0.40 \pm 0.02$ \\
\hline C16:0 & $25.46 \pm 0.15$ & $23.11 \pm 0.30$ & $18.51 \pm 0.15$ \\
\hline C16:1 & $7.83 \pm 0.09$ & $0.88 \pm 0.04$ & nd \\
\hline C17:0 & $0.93 \pm 0.10$ & $0.68 \pm 0.03$ & $0.45 \pm 0.01$ \\
\hline C17:1 & $0.68 \pm 0.01$ & $0.08 \pm 0.01$ & nd \\
\hline C18:0 & $11.97 \pm 0.54$ & $6.33 \pm 0.28$ & $3.09 \pm 0.37$ \\
\hline C18:1n9 & $22.16 \pm 0.36$ & $15.68 \pm 0.14$ & $19.80 \pm 0.31$ \\
\hline $\mathrm{C} 18: 2 \mathrm{n} 6 \mathrm{c}$ & $7.89 \pm 0.07$ & $19.80 \pm 0.01$ & $31.63 \pm 0.06$ \\
\hline C18:3n6 & $0.20 \pm 0.01$ & $0.16 \pm 0.01$ & nd \\
\hline C18:3n3 & $0.50 \pm 0.02$ & $5.01 \pm 0.02$ & $10.25 \pm 0.28$ \\
\hline C20:0 & $0.34 \pm 0.02$ & $0.91 \pm 0.05$ & $0.20 \pm 0.02$ \\
\hline C20:1 & $0.09 \pm 0.01$ & $0.27 \pm 0.02$ & $0.08 \pm 0.01$ \\
\hline $\mathrm{C} 20: 2$ & nd & $0.06 \pm 0.01$ & $0.13 \pm 0.01$ \\
\hline $\mathrm{C} 20: 5 \mathrm{n} 3$ & $0.99 \pm 0.01$ & $0.24 \pm 0.03$ & $0.39 \pm 0.01$ \\
\hline $\mathrm{C} 22: 0$ & $1.05 \pm 0.05$ & $1.23 \pm 0.01$ & $0.27 \pm 0.03$ \\
\hline C24:0 & $1.12 \pm 0.30$ & $1.80 \pm 0.07$ & $0.67 \pm 0.01$ \\
\hline Total SFA (\%) & $58.34 \pm 0.33^{\mathrm{a}}$ & $56.85 \pm 0.14^{\mathrm{a}}$ & $37.24 \pm 0.53^{b}$ \\
\hline Total MUFA (\%) & $32.08 \pm 0.25^{\mathrm{a}}$ & $17.88 \pm 0.18^{\mathrm{c}}$ & $20.34 \pm 0.30^{b}$ \\
\hline Total PUFA (\%) & $9.58 \pm 0.08^{\mathrm{c}}$ & $25.27 \pm 0.04^{b}$ & $42.42 \pm 0.23^{\mathrm{a}}$ \\
\hline$\alpha$-Tocopherol & nd & $0.80 \pm 0.01^{\mathrm{a}}$ & $0.34 \pm 0.01^{\mathrm{b}}$ \\
\hline$\beta$-Tocopherol & $2.09 \pm 0.03^{b}$ & $2.18 \pm 0.06^{\mathrm{a}}$ & $1.72 \pm 0.04^{\mathrm{c}}$ \\
\hline$\gamma$-Tocopherol & nd & nd & $0.91 \pm 0.06$ \\
\hline Sum $(\mathrm{mg} / 100 \mathrm{~g})$ & $2.09 \pm 0.03^{b}$ & $2.98 \pm 0.07^{\mathrm{a}}$ & $2.97 \pm 0.02^{\mathrm{a}}$ \\
\hline
\end{tabular}

FDG: freshly dried ginger; DG: dried ginger; PDG: powder dried ginger; nd (not detected); Caproic Acid (C6:0); Caprylic Acid (C8:0); Capric Acid (C10:0); Undecanoic Acid (C11:0); Lauric Acid (C12:0); Tridecanoic Acid (C13:0); Myristic Acid (C14:0); Myristoleic acid (C14:1); Pentadecanoic Acid (C15:0); CIS-10-Pentadecenoic Acid (C15:1); Palmitic Acid (C16:0); Palmitoleic Acid (C16:1); Heptadecanoic Acid (C17:0); cis-10-Heptadecenoic Acid (C17:1); Stearic Acid (C18:0); Oleic Acid (C18:1n9c); Linoleic Acid (C18:2n6c); Linolenic Acid (C18:3n6); $\alpha$--Linolenic Acid (C18:3n3); Arachidic Acid (C20:0); cis-11-Eicosenoic Acid (C20:1n9); cis-11,14-Eicosadienoic Acid (C20:2); Eicosapentaenoic Acid (C20:5n3); Behenic Acid (C22:0); Lignoceric Acid (C24:0). In each line different letters mean significant differences $(p<0.05)$. 
Table 3. Bioactive compounds and antioxidant activity of the studied ginger dried forms.

\begin{tabular}{lccc}
\hline & FDG & DG & PDG \\
\hline Total phenolics (mg GAE/g extract) & $160.13 \pm 4.39^{\mathrm{b}}$ & $169.59 \pm 1.43^{\mathrm{a}}$ & $128.43 \pm 0.59^{\mathrm{c}}$ \\
Total flavonoids (mg CE/g extract) & $8.81 \pm 0.59^{\mathrm{b}}$ & $13.52 \pm 0.41^{\mathrm{a}}$ & $8.10 \pm 0.40^{\mathrm{c}}$ \\
& & & \\
EC $_{50}$ values (mg/mL) & & & \\
DPPH radical-scavenging activity & $0.36 \pm 0.01^{\mathrm{b}}$ & $0.29 \pm 0.01^{\mathrm{c}}$ & $0.42 \pm 0.01^{\mathrm{a}}$ \\
Reducing power & $0.24 \pm 0.01^{\mathrm{b}}$ & $0.23 \pm 0.01^{\mathrm{c}}$ & $0.36 \pm 0.01^{\mathrm{a}}$ \\
$\beta$-carotene bleaching inhibition & $0.92 \pm 0.03^{\mathrm{b}}$ & $0.61 \pm 0.12^{\mathrm{c}}$ & $1.58 \pm 0.03^{\mathrm{a}}$ \\
TBARS inhibition & $0.15 \pm 0.01^{\mathrm{b}}$ & $0.12 \pm 0.01^{\mathrm{c}}$ & $0.23 \pm 0.01^{\mathrm{a}}$ \\
\hline
\end{tabular}

FDG: freshly dried ginger; DG: dried ginger; PDG: powder dried ginger; GAE- Gallic acid equivalents; CE- Catechin equivalents. The results of the antioxidant activity are presented in $\mathrm{EC}_{50}$ values higher values correspond to lower reducing power or antioxidant potential. $\mathrm{EC}_{50}$ : Extract concentration corresponding to $50 \%$ of antioxidant activity or 0.5 of absorbance for the reducing power assay. In each line different letters mean significant differences $(p<0.05)$. 


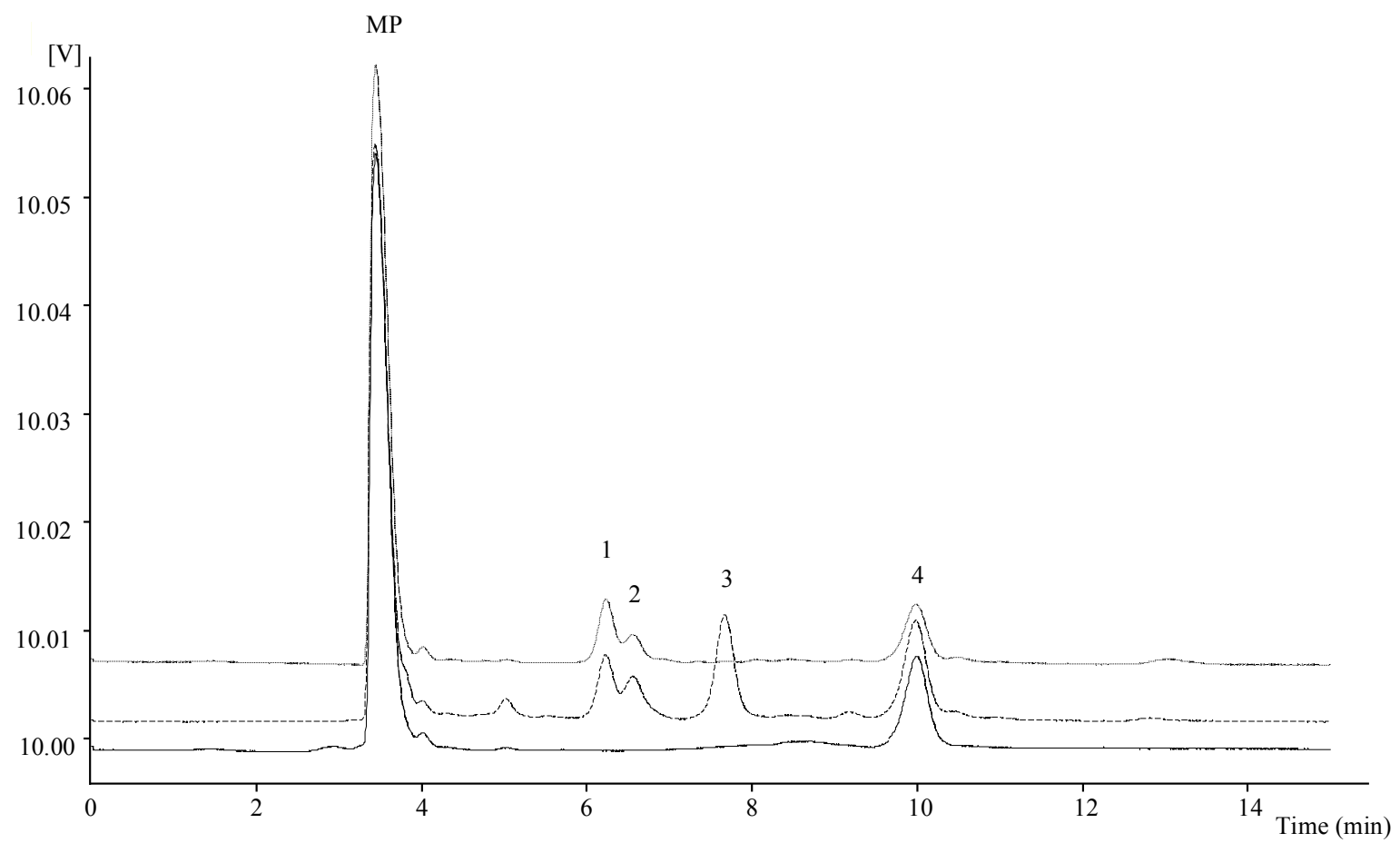

A

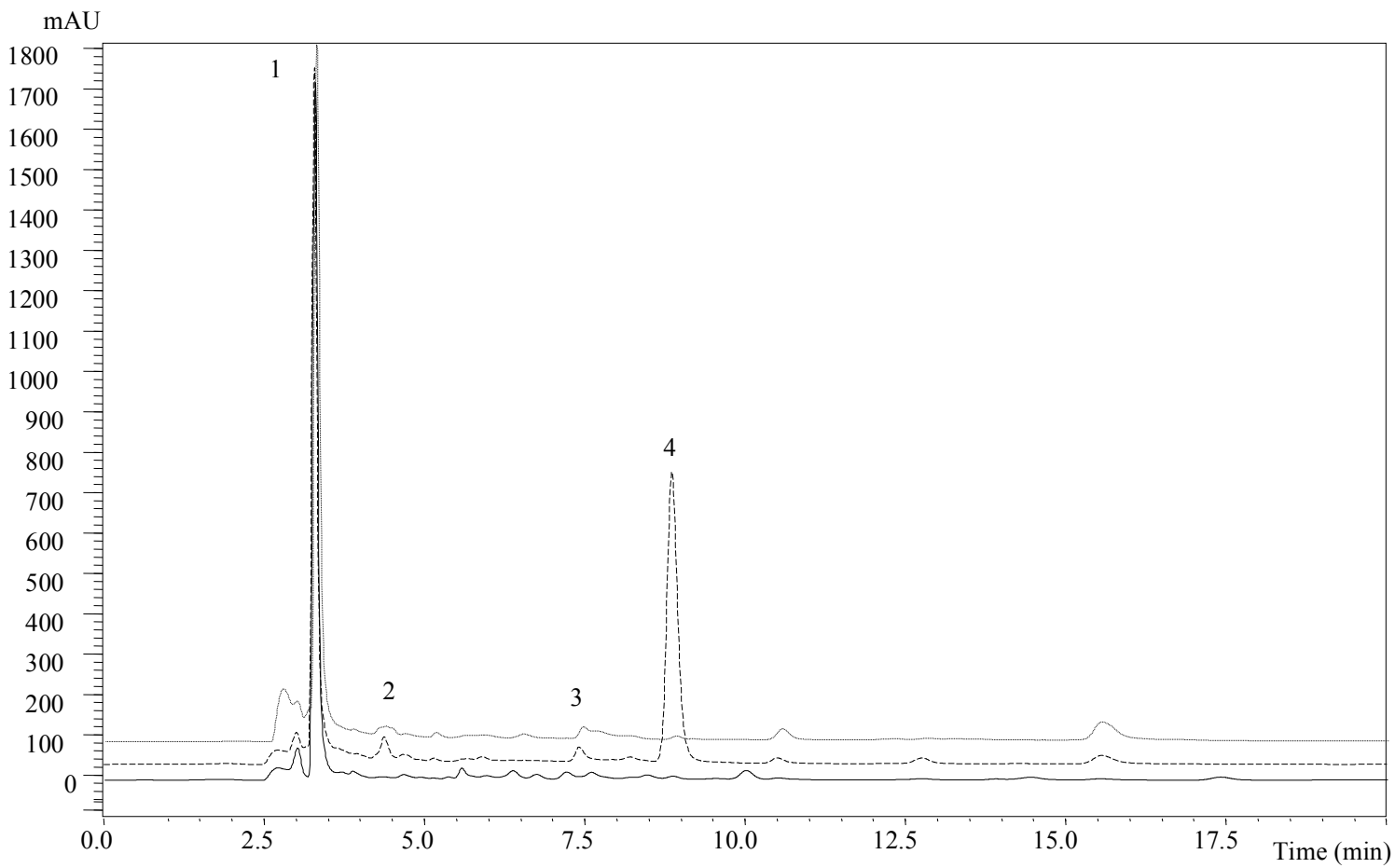

Figure 1. Individual profile of FDG (-), DG (----) and PDG (.....) in (A) sugars: 1- fructose, 2- glucose, 3- sucrose and 4- melezitose (IS) and MP- mobile phase; (B) organic acids: 1oxalic acid, 2- malic acid, 3- citric acid and 4- fumaric acid. 


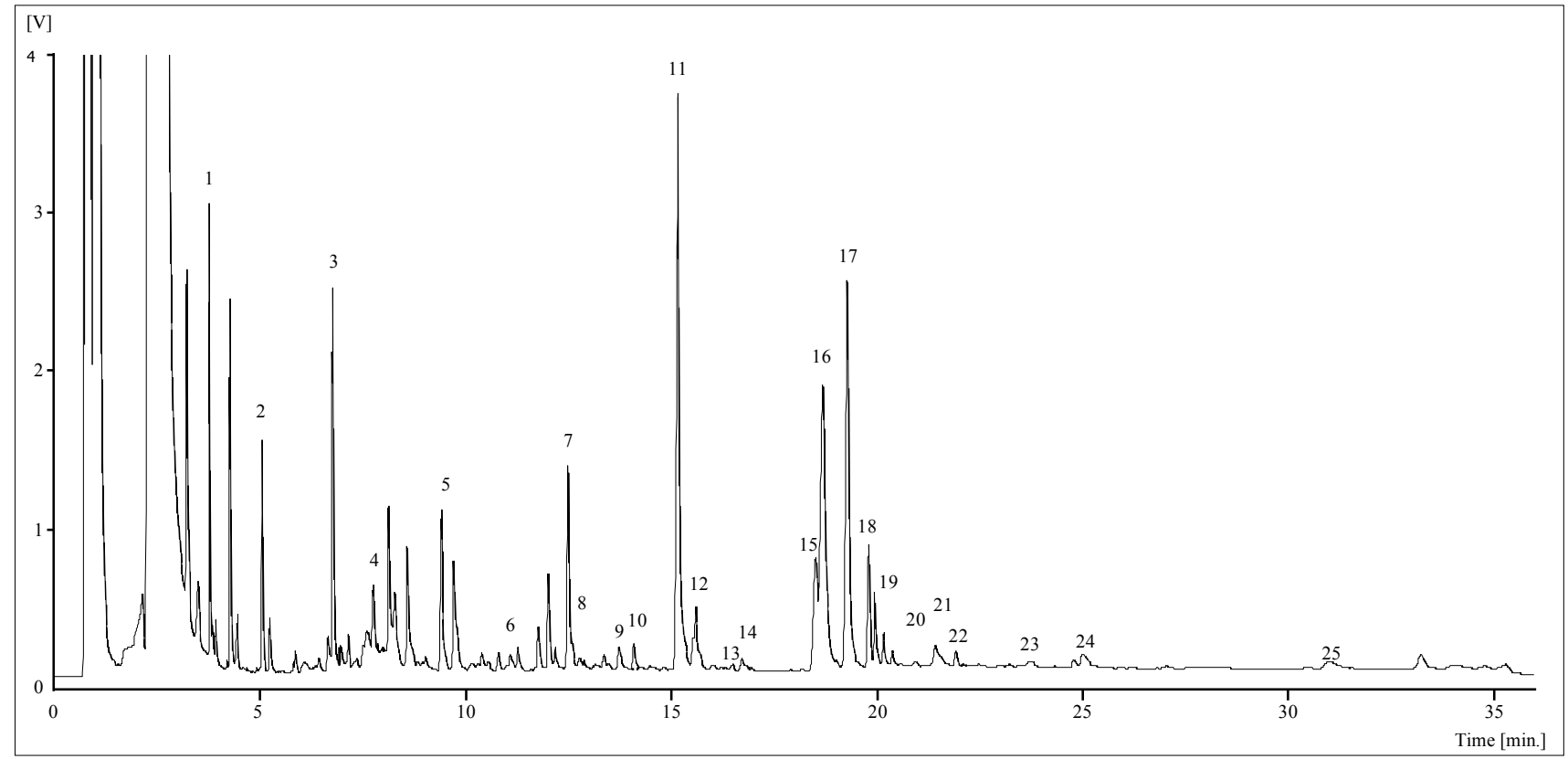

Figure 2. Fatty acids individual profile of DG: 1- C6:0; 2- C8:0; 3- C10:0; 4- C11:0; 5C12:0; 6- C13:0; 7- C14:0; 8- C14:1; 9- C15:0; 10- C15:1; 11- C16:0; 12- C16:1; 13- C17:0; 14- C17:1; 15- C18:0; 16- C18:1n9c; 17- C18:2n6c; 18- C18:3n6; 19- C18:3n3; 20- C20:0; 21- C20:1n9; 22- C20:2; 23- C20:5n3; 24- C22:0; 25- C24:0. 